\title{
Porcine IgG: structure, genetics and evolution
}

\author{
J. E. Butler • Nancy Wertz • Nicolas Deschacht • \\ Imre Kacskovics
}

Published online: 23 January 2009

(C) Springer-Verlag 2009

\section{Erratum to: Immunogenetics}

\section{DOI 10.1007/s00251-008-0336-9}

Reference to the work of

Mendicino M, Ramsoondar J, Phelps C, Vaught T, Ball S, Dai Y, LeRoith T, Monahan J, Chen S, Dandro A, Boone J, Jobst P, Vance A, Wertz N, Polejaeva I, Butler J, Ayares D, Wells K (2008) Targeted disruption of the porcine immunoglobulin heavy chain locus produces a B cell null phenotype. Nature Biotechnology (pending)

in our manuscript was incorrectly cited. This reference should have been cited as "unpublished data" with no reference to which journal the work has or will be submitted.

The online version of the original article can be found at http://dx.doi. org/10.1007/s00251-008-0336-9

J. E. Butler $(\bowtie) \cdot N$. Wertz

Department of Microbiology and Interdisciplinary

Immunology Program, The University of Iowa,

Iowa City, IA 52242, USA

e-mail: john-butler@uiowa.edu

\section{N. Deschacht}

Laboratory of Cellular and Molecular Immunology,

Vrije Universiteit Brussels,

Pleinlaan 2,

B-1050 Brussels, Belgium

N. Deschacht

Department of Molecular and Cellular Interactions, VIB,

Brussels, Belgium

\section{Kacskovics}

Department of Immunology, Faculty of Science, Eotovos Lorand

University and Immunology Research Group of the Hungarian,

Academy of Sciences at Eotvos Lorand University,

Budapest, Hungary 